\title{
Comparativo de los Marcos Normativos para Operaciones de Interceptación de Aeronaves Civiles en Bolivia, Colombia, Perú y México
}

Alfredo Fernández de Lara Gaitán y Rodrigo Mezú

\section{Introducción}

Entre los países de América Latina que cuentan con legislaciones que permiten el derribo de aviones se encuentran Argentina, Bolivia, Brasil, Chile, Honduras, Perú y Venezuela. En contraste, un país como México, donde operan poderosos cárteles del narcotráfico y que además comparte una frontera de más de tres mil kilómetros con los Estados Unidos de América, no permite el derribo de aeronaves ilícitas.

En esta sección del libro, se tiene como objetivo realizar un análisis, en perspectiva comparada, de cuatro casos regionales que disponen de procedimientos en la implementación de operaciones de interdicción aérea. En el análisis comparado, se evidencia que los casos descritos presentan similitudes y diferencias jurídicas y en los alcances que pueden tener las operaciones de interdicción aérea.

Por un lado, se encuentra el caso de Colombia como un país pionero, junto con Perú, en la implementación, a mediados de la década de 1990, de operaciones de interdicción de aeronaves ilegales con el Air Bridge Denial Program (ABDP), el cual contó con la asesoría de agencias estadounidenses. 
Sin embargo, Colombia no posee una legislación nacional referente al tema y hay una cierta ambigüedad sobre el origen del sustento jurídico que permite las operaciones de interdicción aérea en el país. No obstante, desde 1993, mediante un Acta de un Consejo de Seguridad se han realizado operaciones de interceptación de aeronaves hostiles e incluso la neutralización de éstas, tanto en aire como en tierra. En el caso colombiano se permite la "neutralización" e "inutilización" de la aeronave hostil; es decir, el uso de la fuerza para minimizar o evitar la amenaza presentada. De hecho, Colombia se ubica como un país con un fuerte liderazgo regional en operaciones de interdicción aérea; tanto, que se ha convertido en un exportador de experiencias mediante la cooperación sur-sur con diversos países de la región andina, de Centroamérica y Norteamérica.

En el caso de México, desde la segunda mitad de la década de 1990, se realizan operaciones de interceptación aérea contra aeronaves ilícitas rebeldes. Estas operaciones consisten en hacerlas aterrizar o en seguirlas hasta su destino, pero sin la posibilidad de derribarlas o hacer uso de armas de fuego, salvo que sea un acto defensivo y siempre como última opción. La reglamentación aplicable para la interceptación de aeronaves civiles es parte del marco normativo de la Agencia Federal de Aviación Civil, antes Dirección General de Aeronaútica Civil.

Por otro lado, en lo referente a Bolivia y Perú, ambos países andinos disponen de legislaciones nacionales específicas para la vigilancia, el control y la defensa del espacio aéreo nacional, las comúnmente denominadas "leyes de derribo". Ambas legislaciones son relativamente recientes y han sido ratificadas por los legislativos de esos países.

En resumen, el panorama jurídico y, por ende, los lineamientos, procedimientos y alcances de las operaciones de interdicción aérea presentan variaciones en algunos países de la región, como se detallará a continuación.

\section{Perú}

Como se ha señalado, Perú y Colombia fueron Estados pioneros en la región en lo que respecta a las labores de interdicción aérea. Como parte de la lucha contra las drogas se implementó el Air Bridge Denial Program (ABDP), el cual era operado conjuntamente con la Agencia Central de Inteligencia de los Estados Unidos (CIA, por sus siglas en inglés). El principal objetivo del 
ABDP consistía en reducir el transporte de precursores químicos ${ }^{38}$ y de narcóticos por vía aérea haciendo operaciones de interdicción área con la posibilidad de hacer uso de fuerza letal; es decir, derribar las aeronaves consideradas sospechosas y declaradas como hostiles. Sin embargo, en 2001, después de un incidente en el que un avión de la Fuerza Aérea del Perú (FAP), en una operación llevada a cabo en cooperación con la CIA, derribó un avión que transportaba a misioneros estadounidenses ${ }^{39}$ las operaciones de interdicción aérea en el espacio aéreo de Perú se detuvieron (ver capítulos uno y dos).

No obstante, en agosto de 2015, el Congreso de ese país aprobó una legislación que establece las consideraciones y procedimientos bajo los cuales se permite el derribo de aeronaves hostiles. En esta legislación se hace una conceptualización explícita de las definiciones relacionadas con el objeto de la Ley de Control, Vigilancia y Defensa del Espacio Aéreo Nacional (Ley $30339,2015)$. En el artículo 3 se define al espacio aéreo nacional ${ }^{40}$ y en el artículo 5 se establece que, en caso de violación del espacio aéreo nacional con fines ilícitos por parte de una aeronave se entenderá dicha acción como un acto hostil. También se consideran actos hostiles:

La amenaza contra instalaciones estratégicas para el funcionamiento del país, servicios públicos esenciales, la población, sus recursos, las Fuerzas Armadas y la Policía Nacional del Perú; así como cualquier maniobra que atente contra la aeronave interceptora durante los procedimientos de interceptación o el reiterado e injustificado desacato a las instrucciones de la tripulación de la aeronave interceptora. (Ley 30339, 2015)

En la citada legislación peruana se establecen las situaciones que serán consideradas como actos hostiles, entre los cuales se encuentran los siguientes:

a) Aeronave que ingrese al espacio aéreo nacional y no se identifique, ignorando los requerimientos de las autoridades aéreas civiles o militares.

38 Los precursores químicos son sustancias y productos químicos esenciales que pueden ser utilizados por la industria, las farmaceuticas y con fines cientificos; no obstante, también dadas sus características y componentes, con frecuencia se utilizan en la elaboración de estupefacientes (Subsecretaría de lucha contra el Narcotráfico, 2016).

39 ABC News. (3 de febrero de 2010). Mother and Infant Shot Out of the Sky [Archivo de vídeo]. Recuperado de https://www.youtube.com/watch?v=XgOU6MtTblA

40 En el artículo 3 se define al espacio aéreo como "aquel ubicado sobre el suelo, aguas continentales, aguas interiores y mar adyacente que se encuentra bajo la soberanía y jurisdicción del Estado peruano" (Ley 30339, 2015). 
b) Aeronave que no exhiba de manera visible en su exterior los distintivos de su nacionalidad y matrícula o en la que estos sean falsos o adulterados. c) Aeronave que fuese sorprendida arrojando elementos dentro del territorio del Perú contraviniendo la normativa nacional.

d) Aeronave que realice vuelos en el espacio aéreo nacional infringiendo la normativa nacional o internacional aplicable al Estado peruano, relativa a la circulación aérea.

e) Aeronave que ingrese sin autorización a una zona prohibida o zona restringida.

f) Aeronave que no respete los corredores establecidos por las autoridades aeronáuticas civiles o militares.

g) Aeronave que esté volando sin autorización a una altura menor de tres mil (3000) pies.

h) Aeronave que opere en pista no autorizada o sin plan de vuelo.

i) Aeronave respecto de la cual exista evidencia o sospecha razonable de que esté siendo utilizada con el propósito de causar la muerte, lesiones graves a las personas, o daños graves a los bienes o al medio ambiente.

j) Aeronave respecto de la cual exista evidencia o sospecha razonable de que esté siendo utilizada para la comisión del delito de tráfico ilícito de drogas.

k) Aeronave respecto de la cual exista evidencia o sospecha razonable de que esté transportando ilícitamente: 1) Bombas, armas, armas de fuego, armas de fuego artesanales, municiones, materiales explosivos, inflamables, asfixiantes, tóxicos, sustancias o materiales destinados para su preparación. 2) Minas antipersonales o minas antipersonales artesanales.

1) Aeronave que, una vez interceptada, no acate las instrucciones de la tripulación de la aeronave interceptora; registre una actitud evasiva; o intente darse a la fuga.

m) Aeronave desde la cual, una vez interceptada, se arrojen elementos fuera de esta.

n) Aeronave desde la cual, una vez interceptada, se efectúen maniobras, actos o amenazas contra la seguridad de la aeronave interceptora.

o) Aeronave que, sin contar con la autorización de las autoridades aeronáuticas civiles o militares, se encuentre en un aeródromo no autorizado, en un aeródromo no controlado, fuera de un aeródromo o en un cuerpo de agua. (2015) 
La aeronave que incurra en alguna de las situaciones arriba señaladas podrá ser declarada como hostil por el comandante del Comando Operacional de Defensa Aérea, lo que implica que se considere una amenaza a la seguridad y una violación a la soberanía peruana.

El procedimiento hacia una aeronave declarada como hostil consiste en que la tripulación de la aeronave interceptora busca comunicar a la tripulación de la otra aeronave que ésta ha sido declarada como "hostil" y, por lo tanto, se podrá proceder a su neutralización mediante el uso de la fuerza. La comunicación hacia la nave hostil se hará mediante un mensaje de radiotelefonía en español e inglés.

Una vez seguidos los principios, lineamientos y procedimientos de interceptación establecidos en la legislación (artículos 6, 9, 10, 11 y 12), si la aeronave declarada hostil ignora y/o desacata las instrucciones de las aeronaves de la FAP asignadas para su intercepción, el Comando Operacional de Defensa Aérea, autorizará "el empleo de la fuerza para minimizar o evitar la amenaza" (Ley 30339, 2015).

De particular interés resulta el artículo 11, ya que en este se indican los lineamientos generales para los procedimientos de interceptación de una aeronave en vuelo. En estos se indican las medidas a seguir, tales como la identificación, la intervención, la persuasión y, en última medida, la neutralización de la aeronave declarada como hostil. De acuerdo con el artículo 11 esas medidas consisten en lo siguiente:

11.2 Las medidas de identificación tienen por finalidad determinar o confirmar la identidad de una aeronave o vigilar su comportamiento. Tales medidas incluyen el reconocimiento a distancia, la confirmación de la matrícula, la aproximación de la aeronave interceptora a la aeronave interceptada para efectuar el interrogatorio por medio de mensajes de radiotelefonía y la realización de señales visuales, de conformidad con las reglas internacionales aeronáuticas.

11.3 Las medidas de intervención se efectúan a continuación de las medidas de identificación, en caso de que estas últimas no hayan tenido éxito. Consisten en indicar a la aeronave interceptada que regrese a su derrota planeada, que se dirija más allá de los límites del espacio aéreo nacional, que salga de una zona prohibida, restringida o peligrosa u obligarla a aterrizar en el aeródromo que le fuera determinado, para ser sometida a medidas de control, incluyendo el guiado de la aeronave interceptada para los efectos antes señalados realizado por la aeronave interceptora. 
11.4 Las medidas de persuasión se efectúan a continuación de las medidas de intervención, en caso de que estas últimas no hayan tenido éxito. Consisten en el disparo de ráfagas de advertencia con munición trazadora por la aeronave interceptora, de manera que puedan ser observadas por la tripulación. (Ley 30339, 2015)

En el artículo 12 se establecen los lineamientos y procedimientos de interceptación para aeronaves que se encuentren en tierra; es decir, en un aeródromo no autorizado, en un aeródromo no controlado o en un cuerpo de agua. También se incluyen medidas progresivas de identificación, intervención, persuasión y neutralización a cargo de la FAP.

Según lo establecido en el artículo 14 de la mencionada ley, los procedimientos de interceptación a aeronaves tienen que quedar bajo registro por medios audiovisuales o algún otro medio viable. Esto con el objetivo de evidenciar que se cumplió con los lineamientos y procedimientos establecidos en la legislación.

\section{Colombia}

Desde mediados de la década de 1990, Estados Unidos comenzó a trabajar simultáneamente con Colombia y Perú en operaciones de interdicción aérea de vuelos ilegales con el objetivo de frenar el trasiego de narcóticos desde Sudamérica hacia ese país. Las operaciones conjuntas consistían en compartir inteligencia, recursos como aviones y radares, y la capacitación de personal militar colombiano y peruano para las operaciones de intercepción de aeronaves sospechosas y, en su caso, el derribo de aeronaves que se negaran a aterrizar y fueran declaradas una amenaza.

Sin embargo, el 20 de abril de 2001, el incidente ocurrido en Perú (el derribo, por parte de la FAP, de una aeronave en la cual viajaban cinco ciudadanos estadounidenses, dos de los cuales fallecieron) llevó a la suspensión de la colaboración estadounidense con ese país y con Colombia ${ }^{41}$ (ver capítulos uno y dos). Este incidente, que se produjo en una operación de interdicción de la Fuerza Aérea de Perú que contaba con apoyo de inteligencia de una aeronave P-3 Orión de la $\mathrm{CIA}^{42}$, puso en evidencia una cadena de errores y

41 Gómez, S. (26 de abril de 2001). E.U. suspende interceptación aérea. El Tiempo [en línea]. Recuperado de https:/www.eltiempo.com/archivo/documento/MAM-541122

42 Páez, A. (9 de fecbrero de 2010). Perú: CIA y militares discrepan en caso de avión de mi- 
mostró las vulnerabilidades que se podían producir durante el proceso de interdicción de aeronaves civiles. Por ejemplo, las limitaciones en el manejo del idioma inglés que tenían los pilotos peruanos encargados de la intercepción de la aeronave. En consecuencia, estos acontecimientos, llevaron a que se replantearan y se implementaran mejoras en los protocolos y procedimientos de interdicción aérea.

De hecho, las operaciones de interdicción aérea entre Colombia y EE. UU. se reactivaron poco más de dos años después del lamentable derribo de la aeronave civil en Perú. Sin embargo, una externalidad positiva de esta situación consistió en que Colombia amplió su autonomía y sus capacidades en materia de interdicción aérea. En otras palabras, se pasó de solo ejecutar la interdicción con aeronaves de la FAC a realizar el seguimiento mediante aviones con radares, entretanto EE. UU. continuó dando las alertas con sus plataformas ${ }^{43}$.

Ahora bien, en el caso colombiano no se dispone de una legislación nacional para el derribo de aeronaves ilícitas, aunque, desde 1993, se habilitó este procedimiento mediante un Acta de un Consejo de Seguridad. Sin embargo, lineamientos más precisos se pueden encontrar en los Reglamentos Aeronáuticos de Colombia (RAC), específicamente en el apéndice D y Adjunto 1 del apéndice D del Reglamento del Aire, RAC 5, en los que se encuentran diversas disposiciones, entre ellas las relacionadas con los procedimientos para la interceptación de aeronaves civiles.

En el numeral 2 del Adjunto 1 del apéndice D indica que "la interceptación de aeronaves civiles se emprenderá como último recurso", privilegiando que "las dependencias de control de interceptación hagan todo lo posible para asegurar la identificación de cualquier aeronave que pueda ser una aeronave civil" y haciendo "todo lo posible para garantizar la coordinación entre las dependencias de tierra y los pilotos de que se trate" (UAEAC, s.f., p. 3).

En esta normativa se establece que los pilotos de las aeronaves interceptoras deben estar al tanto de las limitaciones generales y de la posibilidad de que la aeronave en seguimiento pueda encontrarse en una situación de emergencia o con fallas técnicas. Para reducir la posibilidad de errores en el citado adjunto 1 del apéndice del RAC 5, numeral 3, se establecen detalladamente

sioneros. Inter Press Service [en línea]. Recuperado de http://www.ipsnoticias.net/2010/02/ peru-cia-y-militares-discrepan-en-caso-de-avion-de-misioneros/

43 Colprensa. (3 de septiembre de 2002). Comandante de la FAC revela avances del proceso de interdicción "vamos a usar radares propios con radares. El País. C12, B91. 
las previsiones que se tienen que tomar en las maniobras de interceptación; por ejemplo, el procedimiento de tres fases a seguir para la identificación visual, a fin de no poner en riesgo innecesario a la aeronave civil en proceso de ser interceptada.

En esta normativa también se establece que la nave interceptora buscará entablar comunicación por radio con la aeronave declarada ilícita y se disponen explícitamente un compendio de frases, incluidas las pronunciaciones, que deben seguirse. También se indican las señales visuales que se utilizan en caso de interceptación.

Las decisiones que se pueden seguir son: la permisión (se autoriza a la aeronave interceptada continuar su vuelo, una vez aclarada su situación), la rendición, la inmovilización o la neutralización de las aeronaves por parte de la Fuerza Aérea Colombiana. En el caso específico de la "rendición" esta consiste en que la aeronave interceptada obedezca las indicaciones y proceda a dirigirse a aterrizar donde le sea indicado y quede bajo control de las fuerzas públicas en la superficie. La "inmovilización" se refiere a "impedir la movilización de un aeronave después de aterrizar, hasta el momento en que se haga presente una autoridad judicial competente con el fin de ponerla en conocimiento de los hechos y a órdenes de la misma" (UAEAC, s.f., p. 77).

Según el numeral 11.3. de esta normativa, una aeronave será considerada como "hostil" cuando haya registro de una violación al espacio aéreo de Colombia.

\begin{abstract}
Por parte de una aeronave con fines presuntamente ilícitos o la indicación de una amenaza contra instalaciones gubernamentales, centros vitales de la Nación, la población, sus recursos y la Fuerza Pública, así como también cualquier maniobra que atente contra la aeronave interceptora dentro de un proceso de interceptación o el reiterado e injustificado desacato de las instrucciones. (UAEAC, s.f., p. 78)
\end{abstract}

Una vez la aeronave es declarada como hostil deja de ser considerada como una aeronave civil, por lo que se permite "la aplicación de la fuerza para minimizar o evitar la amenaza" (s.f). En el citado numeral también se especifican cuáles son las situaciones para considerar la existencia de una amenaza ${ }^{44}$.

44 En el Reglamento Aeronautico de Colombia Rac 5, "se considera que existe una amenaza frente a los siguientes casos: 1) Una aeronave que ingrese a una Zona Prohibida, sin autorización. 2) Una aeronave que esté volando a una altura menor de 3000 pies en un radio de 40 millas náuticas de una cabeza radar y/o de una Unidad Militar, sin identificarse. 3) Aeronave militar 
La "inutilización” consiste en la aplicación de la fuerza para dejar inoperativa la aeronave declarada hostil. Por su parte, la "neutralización" se define como la "acción de impedir que una aeronave catalogada como hostil cumpla la amenaza presentada con la violación del espacio aéreo. La neutralización abarca desde la desviación, la inmovilización hasta la inutilización preferiblemente en tierra" (s.f., p. 78). Esta declaratoria y la orden de neutralización puede ser emitida únicamente por el Comandante de la FAC.

El procedimiento indica cinco fases para la neutralización de las aeronaves. Las fases I, II y III son las fases de "interceptación”. Este proceso incluye los intentos por establecer contacto por radio y/o mediante señales visuales para establecer la identidad de la aeronave y del piloto de la aeronave en proceso de interceptación. Si el piloto de la aeronave interceptada procede a cumplir con las indicaciones de la aeronave interceptora de la FAC y acepta la guía para aterrizar en el campo designado, se culmina con estas fases. En caso contrario, cuando el piloto de la aeronave interceptada se niega a cumplir con las indicaciones realizadas por la aeronave interceptora, la primera podrá ser clasificada como "hostil" y se procederá con la fase IV, denominada como "advertencia". En este punto, cuando el piloto de la aeronave interceptada persiste en mantener silencio o hacer caso omiso de las señales visuales, el piloto de la aeronave interceptora se ubicará lateral de la primera con el objetivo de que el piloto interceptado:

extranjera que ingrese al espacio aéreo de Colombia sin autorización. 4) La aeronave que una vez interceptada no atiende las instrucciones del interceptor ó registre una actitud evasiva, de agresión o ataque. 5) Aeronave que se encuentre aterrizada en un aeródromo ilegal, sin autorización de la Unidad Administrativa Especial de la Aeronáutica Civil UAEAC o acuatizada en lugar no autorizado por dicha autoridad. 6) Aeronave en operación nocturna desde pistas no autorizadas o sin plan de vuelo. 7) Aeronave que una vez interceptada, arroje objetos o elementos fuera de esta y que de forma sistemática desatienda las instrucciones de la aeronave interceptora. 8) Aeronave que sobrevuele sin autorización a una altura inferior a 3.000 pies cualquier instalación militar. 9) Aeronave que no ostente ningún distintivo de nacionalidad y matrícula o que estos sean falsos. 10) Aeronave desde la cual, una vez interceptada se efectúan actos de agresión o amenaza contra la interceptora" (UAEAC, s.f., pp. 78-79).

Según el reglamento antes mencionado, "no se aceptará la declaración por parte del piloto de la aeronave interceptada, en situación de emergencia por interferencia ilícita (secuestro) o por motivos técnicos, después de realizada una interceptación, con el fin de evitar el cumplimiento de las órdenes emitidas por el interceptor, cuando no haya sido reportada esta situación como tal a la autoridad ATS competente oportunamente y antes de iniciarse la interceptación" (UAEAC, s.f., p. 79). 
Pueda observar las ráfagas de advertencia con trazadora, mientras por frecuencia de emergencia se enuncia que en el momento se están realizando disparos disuasivos y que si no se atienden las instrucciones la aeronave será considerada hostil y como tal, podría ser inutilizada. (UAEAC, s.f., p. 80)

Finalmente, la Fase V se implementa cuando "se registra una respuesta negativa o agresiones de la aeronave interceptada, una vez considerada hostil podría ser necesario inutilizarla" ${ }^{45}$.

\section{Bolivia}

El 22 de abril de 2014, el entonces presidente Evo Morales promulgó la Ley 521 de Seguridad y Defensa del Espacio Aéreo. De acuerdo con el artículo 1, el objeto de esta ley es "establecer y regular medidas, acciones y procedimientos para el control, vigilancia y defensa del espacio aéreo del Estado Plurinacional de Bolivia en ejercicio de su soberanía” (Ley 521, 2014). $\mathrm{Y}$ es aplicable a "los objetos, aparatos y aeronaves civiles, nacionales y/o extranjeras que se encuentren operando en territorio y espacio aéreo del Estado Plurinacional de Bolivia" (2014, p. 1). En esta ley se establecen "los procedimientos de interceptación de aeronaves civiles y el empleo de la fuerza contra aeronaves declaradas infractoras, ilícitas u hostiles" (2014, p. 1).

La legislación boliviana (artículo 6) define tres tipos de aeronaves susceptibles de ser obligadas a aterrizar o a ser derribadas: las aeronaves infractoras, ilícitas y/u hostiles. Las aeronaves infractoras:

Son aquellas que, por su conducta voluntaria o involuntaria, modifican su plan de vuelo original sin notificar al control de tránsito aéreo; vulneran

45 Según el Reglamento Aeronáutico de Colombia Rac 5, "la Fuerza Aérea Colombiana no hará uso de la fuerza contra aeronaves hostiles cuando se presenten las siguientes situaciones: a) Cuando se encuentren sobrevolando una concentración de personas o edificaciones y que afecten a la población civil, excepto cuando el centro urbano haya sido declarado zona prohibida por razones de seguridad o cuando se presente una amenaza de daño físico al personal, o a centros vitales, o a las instalaciones del Gobierno de la República de Colombia. b) Cuando existan fundadas razones para considerar que a bordo de la aeronave viajan personas ajenas a la operación hostil en desarrollo de un vuelo comercial o no. c) Cuando existan fundadas razones para considerar que la aeronave está siendo objeto de un acto de interferencia ilícita o se encuentra en una situación de emergencia, siempre y cuando tales situaciones hayan sido reportadas antes de la declaratoria de aeronave hostil”. (UAEAC, s.f., pp. 90-81). 
o no cumplen las reglamentaciones aeronáuticas; o incumplen órdenes y disposiciones de los controladores aéreos. Estas pueden ser obligadas a aterrizar mediante órdenes o interceptación, de acuerdo con procedimientos establecidos en la reglamentación aeronáutica correspondiente. (Ley 521, 2014, p. 2)

Las aeronaves ilícitas, por su parte:

Son aquellas aeronaves que, en tierra o vuelo, realizan actividades con propósitos incompatibles a las normas de aviación civil internacional: violación del espacio aéreo o actividad delincuencial. Estas aeronaves podrán ser obligadas a aterrizar mediante órdenes o interceptación con el fin de llevarse a cabo los procesos judiciales correspondientes. Las aeronaves infractoras, podrán ser declaradas ilícitas cuando se nieguen a cumplir órdenes y disposiciones reglamentarias. (2014, p. 2)

Por último, las aeronaves hostiles "son aquellas aeronaves que muestran evidentes acciones de agresión, amenaza o intento de fuga. Asimismo, aquellas aeronaves que siendo declaradas ilícitas se nieguen a aterrizar o a cumplir órdenes o disposiciones" (2014, p. 2). Los vuelos hostiles son calificados como una amenaza y una vulneración a la soberanía y seguridad nacional de Bolivia.

En la legislación boliviana, el Sistema Integral de Vigilancia, Control y Defensa del Espacio Aéreo se asigna al Comando de Seguridad y Defensa del Espacio Aéreo y, el Comandante de Seguridad y Defensa del Espacio Aéreo es la máxima autoridad para autorizar el uso de la fuerza o represión en contra de aeronaves que hayan sido declaradas hostiles.

Según el artículo 9, "los procedimientos de interceptación de una aeronave civil se ejecutarán con el propósito de identificarla, brindarle ayuda, obligarla a retornar a su ruta u obligarla a aterrizar, según corresponda, de acuerdo con lo establecido en la Reglamentación Aeronáutica Boliviana correspondiente" (2014, p. 3). Para Bolivia las acciones "preventivas, disuasivas, coercitivas y reactivas" que sean aplicadas son consideradas como "legítima defensa”, por lo que, según el artículo 11, una vez agotadas las acciones preventivas, disuasivas y coercitivas sobre aeronaves declaras hostiles, hecha previa advertencia, se procederá a acciones reactivas de empleo de la fuerza "cuyo resultado puede manifestarse en daños, derribo o destrucción de la aeronave" (2014, p. 3). Lo anterior invocando el derecho a la legítima defensa del Estado. 
En el artículo 13 se establece el caso específico del procedimiento a seguir con las aeronaves civiles involucradas en actividades relacionadas con el narcotráfico. Al respecto se señala que las aeronaves civiles que sean "sorprendidas en actividades de narcotráfico, serán incautadas directamente a favor de las Fuerzas Armadas; de la misma manera a las que fueran detenidas y se establezca su vinculación con el narcotráfico, determinado por autoridad competente, previos procesos legales" (2014, p. 4).

Sumado al proceso de modernización legal y con el fin de dotar de más capacidades al Sistema Integral de Vigilancia, Control y Defensa del Espacio Aéreo, en noviembre de 2015, el Ministerio de Defensa de Bolivia suscribió un contrato con la empresa francesa Thales Air Systems para el suministro de un sistema integrado de defensa y control de tráfico aéreo, con un costo estimado de 225,1 millones de dólares. El contrato incluye 13 radares, cuatro de defensa aérea, un radar primario de vigilancia Star2000, dos radares Trac de aproximación y seis radares civiles RS970 ${ }^{46}$.

\section{México}

Desde las décadas de 1980 y, en particular, a partir de 1990 se hizo evidente que el espacio aéreo de México era ampliamente vulnerable al tráfico aéreo ilegal, ya fuera por falta de capacidades o por omisión (ver capítulo cinco). La Fuerza Aérea Mexicana (FAM) no dispuso, al menos hasta la primera mitad de los años noventa, de las herramientas legales, ni de las capacidades humanas y materiales para vigilar el espacio aéreo mexicano en contra de incursiones de aeronaves sospechosas, ilegales o ilícitas.

Fue durante la administración del presidente Ernesto Zedillo (19942000) que se ordenó a la FAM que procediera a rastrear y, en su caso, interceptar vuelos ilegales y a aquellos que estuvieran realizando operaciones de contrabando de narcóticos. Sin embargo, México no adoptó una ley de derribo; por lo cual, sólo se podían interceptar e intimidar vuelos ilegales para que aterrizaran o para rastrearlos y coordinarlos con los activos terrestres para detenerlos una vez que habían aterrizado (Guevara, 2016).

A la fecha se mantienen estas restricciones para el derribo de aeronaves declaradas ilícitas o rebeldes (según la terminología de la FAM), tal y como

46 Hernández, C. (24 de mayo de 2018). Bolivia presume de comprar los radares más avanzados de la región. Infodefensa.com [en línea]. Recuperado de https://www.infodefensa.com/ latam/2018/05/24/noticia-bolivia-presume-comprar-radares-avanzados-region.html 
lo evidencia la respuesta que la Secretaría de la Defensa Nacional (SEDENA) dio a la solicitud de información con número de folio: 0000700063320. En dicha solicitud se preguntó, entre otras cuestiones, lo siguiente: ¿̨la legislación mexicana permite derribar la aeronave ilícita rebelde? A lo que la SEDENA respondió "Se hace de su conocimiento que actualmente la legislación mexicana no permite derribar aeronaves ilícitas rebeldes" (2019). Es decir, si bien se permite el rastreo, la intercepción de los vuelos y el seguimiento para obligarlos a aterrizar; no se permite el uso de la fuerza para el derribo de las aeronaves ilícitas declaradas como rebeldes.

En lo que respecta a la normatividad bajo la que actualmente se sustenta la interceptación de aeronaves civiles, en dicha solicitud de información se seńaló que:

En México, únicamente se dispone de la normatividad que establece la publicación de información aeronáutica (P.I.A), en su párrafo 1.12 "Interceptación de aeronaves civiles" (Procedimiento Sistemático de Operación para la Interceptación de Aeronaves Ilícitas), el cual en su numeral 7.5 menciona lo siguiente: " ...si la aeronave interceptada continua con su trayectoria de vuelo o con la ruta de vuelo establecida y no da señal alguna de pretender seguir las instrucciones recibidas, será declarada por el C.M.C. SIVA (SEDENA/FAM) como aeronave ilícita rebelde y se vigilará y seguirá hasta su aterrizaje, actuando conforme a lo descrito en el numeral 9....". (SEDENA, 2019)

En el Manual de Publicación de Información Aeronáutica AIP de México, con fecha del 10 de octubre de 2019, en la sección 1.12 "Interceptación de Aeronaves Civiles" se detalla el procedimiento sistemático de operación para la interceptación de aeronaves ilícitas. En dicho documento se señala que:

Los Estados Unidos Mexicanos tienen derecho, en el ejercicio de su soberanía a exigir el aterrizaje en un aeropuerto designado a una aeronave civil que sobrevuele su territorio sin estar facultada para ello o si se tienen motivos razonables para llegar a la conclusión de que se utiliza para propósitos incompatibles con los convenios internacionales.

Lo anterior con fundamento en el artículo 42 fracción VI de la Constitución Política de los Estados Unidos Mexicanos y conforme al inciso B del 
artículo 3 BIS del Protocolo de Montreal de $1984^{47}$. Este protocolo forma parte de la reglamentación del espacio aéreo internacional y surge como consecuencia de un lamentable incidente, el derribo de una aeronave civil de pasajeros de Korean Airlines en septiembre de 1983 y en el cual fallecieron 269 personas. En consecuencia, la Organización de Aviación Civil Internacional (OACI) se enfocó en una reglamentación que conjugara los intereses del Estado y el ejercicio de su soberanía en el espacio aéreo sin menoscabo de la seguridad de la aviación civil (Moyano, 1993).

En el citado documento se señala que la Secretaría de Seguridad y Protección Ciudadana, la Polícia Federal y la Guardia Nacional son las dependencias del gobierno mexicano responsables jurídicamente del combate al narcotráfico y otras actividades que puedan realizarse por la vía aérea. Las fuerzas armadas coadyuvan con la Secretaría de Seguridad y Protección Ciudadana, la Policía Federal y la Guardia Nacional en estas labores.

El Centro de Mando y Control del Sistema Integral de Vigilancia Aérea del Estado Mayor de la Defensa Nacional (CMC.SIVA SEDENA/FAM) está encargado de la vigilancia del espacio aéreo mexicano y, en su caso, de la identificación y seguimiento de aeronaves sospechosas o no identificadas que sean declaradas como aeronaves ilícitas. En el caso que corresponda, éste comunicará la información para que se asignen las directrices y se proceda al despegue de las aeronaves encargadas de la interceptación de la aeronave.

En el Manual de Publicación de Información Aeronáutica AIP de México se establece que la nave interceptora buscará entablar comunicación por radio con la aeronave declarada ilícita y se dispone de un compendio de frases y pronunciaciones que deben seguirse (esto de manera similar a lo establecido en los Reglamentos Aeronáuticos de Colombia (RAC), Apéndice D y Adjunto 1 del Apéndice D del Reglamento del Aire RAC 5.

También se indican las señales visuales que se utilizan en caso de interceptación. Por ejemplo, para indicar "Usted ha sido interceptado. Sígame" se procederá a:

47 El artículo 3 bis del Protocolo de Montreal de 1984 establece que: "a) Los Estados contratantes reconocen que todo Estado debe abstenerse de recurrir al uso de las armas en contra de las aeronaves civiles en vuelo y que, en caso de interceptación, no debe ponerse en peligro la vida de los ocupantes de las aeronaves ni la seguridad de éstas. La presente disposición no se I. Asuntos constitucionales y de política general I-11 interpretará en el sentido de que modifica en modo alguno los derechos y las obligaciones de los Estados estipulados en la Carta de las Naciones Unidas. b) Los Estados contratantes reconocen que todo Estado tiene derecho, en el ejercicio de su soberanía, a exigir el aterrizaje en un aeropuerto designado de una aeronave civil que sobrevuele su territorio sin estar facultada para ello, o si tiene motivos razonables para 
Alabear la aeronave y encender y apagar las luces de navegación a intervalos irregulares (y luces de aterrizaje en el caso de un helicóptero) desde una posición ligeramente por encima y por delante y, normalmente, a la izquierda de la aeronave interceptada (o a la derecha si la aeronave interceptada es un helicóptero) y, después de recibir respuesta, efectuar un viraje lento, normalmente a la izquierda (o a la derecha en el caso de un helicóptero) hacia el rumbo deseado. (s.f., p. 48)

La respuesta positiva ("comprendido lo cumpliré") de la aeronave en proceso de intercepción consistirá en "alabear la aeronave, encender y apagar las luces de navegación a intervalos irregulares, y seguir la nave interceptora” (s.f., p. 48).

Las maniobras para la identificación visual por parte de la aeronave interceptora están comprendidas por tres fases cuyo objetivo principal es la identificación de la aeronave en seguimiento. Es importante que el piloto de la aeronave interceptora este seguro de que ha sido visualizado y sus señales han sido reconocidas por parte del piloto de la aeronave interceptada. Incluso pueden utilizarse para ese fin "otros métodos de señalización, incluso como último recurso el efecto visual del post quemador a reserva de que no se plantee una situación peligrosa para la aeronave interceptada” (s.f. p. 84). Cuando se logré establecer contacto por radio con la aeronave interceptada "se proporcionará por radiotelefonía, la guía de navegación y la información correspondiente" (p. 85) para que aterrice en un aeropuerto cercano al área de interceptación y las fuerzas terrestres correspondientes procedan al aseguramiento "mientras las autoridades correspondientes efectúan su revisión para proceder como legítimamente corresponda" (p. 85).

llegar a la conclusión de que se utiliza para propósitos incompatibles con los fines del presente Convenio; asimismo puede dar a dicha aeronave toda otra instrucción necesaria para poner fin a este acto de violación. A tales efectos, los Estados contratantes podrán recurrir a todos los medios apropiados compatibles con los preceptos pertinentes del derecho internacional, comprendidas las disposiciones pertinentes del presente Convenio y, específicamente, con a) del presente Artículo. Cada Estado contratante conviene en publicar sus reglamentos vigentes en materia de interceptación de aeronaves civiles. c) Toda aeronave civil acatará una orden dada de conformidad con b) del presente Artículo. A este fin, cada Estado contratante incorporará en su legislación o reglamentación todas las disposiciones necesarias para que toda aeronave civil matriculada en él o explotada por un explotador cuya oficina principal o residencia permanente se encuentre en su territorio, tenga la obligación de acatar dicha orden. Cada Estado contratante tomará las disposiciones necesarias para que toda violación de esas leyes o reglamentos aplicables se castigue con sanciones severas, y someterá el caso a sus autoridades competentes de conformidad con las leyes nacionales". (OACI, 2016, p. I-11) 
Si seguidos los procedimientos anteriores la aeronave ignora los señalamientos y continúa con su ruta de vuelo "y no da señal de pretender seguir las instrucciones recibidas, serán declaradas por el Centro de Mando y Control del Sistema Integral de Vigilancia Aérea del Estado Mayor de la Defensa Nacional (CMC.SIVA SEDENA/FAM) como "aeronave ilícita rebelde", se le vigilará y seguirá hasta su aterrizaje, coordinando la interceptación terrestre con las unidades operativas (Secretaría de la Defensa Nacional, Secretaría de Marina, Secretaría de Seguridad y Protección Ciudadana, la Policía Federal y la Guardia Nacional, y/o fuerzas de seguridad públicas estatales).

La normativa citada para el caso mexicano contempla el uso de armas de fuego solo como el último recurso. En el numeral 8 titulado "Política para el uso de armamento con que está dotado el material de vuelo" se menciona bajo qué condiciones se puede aplicar el uso de la fuerza. En el numeral 8.1 se señala:

Si el o las aeronaves interceptor(as) durante el desarrollo de sus actividades es (son) agredido(s) con armas de fuego desde la aeronave ilícita, cuando esta(s) va(n) en vuelo, procederá(n) a repeler la agresión utilizando el armamento con que está dotado(s). Dentro de las posibilidades de maniobra, desempeño y armamento con el cual esté dotado el equipo de vuelo interceptor se deberá mantener como prioridad no dañar, destruir, o inhabilitar una aeronave en servicio.

Por lo tanto, mientras las aeronaves interceptoras no sean agredidas por la aeronave ilícita con armas de fuego no podrán hacer uso de fuerza letal.

Cuando la interceptación se haga en espacio aéreo mexicano se proporcionará a la Fiscalía General de la República la información, registros audiovisuales, imágenes y comunicaciones relacionadas de los Centros de Control Regional y de las aeronaves de vigilancia, seguimiento e interceptación que correspondan a "la vigilancia, seguimiento, identificación, interceptación, aterrizaje y las acciones que realicen los probables delincuentes en el área de aterrizaje y vías de escape, siempre que estén equipadas con estos sistemas", con el objetivo de realizar las posibles investigaciones y judicializaciones.

Desde el 2007, en el marco de un proyecto para modernizar las capacidades de detección del SIVA, se identificó que los radares aéreos eran efectivos, pero los radares terrestres estaban significativamente desactualizados. En el documento Directiva Integral para el Combate al Narcotráfico (SEDENA) 
se describe que las capacidades de detección y seguimiento de los tres radares terrestres Westinghouse TPS-70 3-D (Guevara, 2011), que habían estado en uso desde enero de 1989, no estaban operando al 100\%. El documento mencionado establece que los radares sólo funcionan en modo secundario. En otras palabras, los radares podían proporcionar datos para los controladores de tránsito aéreo, pero eran ineficaces para detectar vuelos de baja altura. Después de considerar varios tipos de radares, la FAM seleccionó el AN / TPS-78 y realizó un pedido de USD 118 millones en 2010, los cuales comenzaron a ser entregados en 2011 (Guevara, 2016, p. 45-46).

\section{Conclusiones}

En la revisión que se hizo se encuentra que dos de los países estudiados, Perú y Bolivia, disponen de legislaciones nacionales en las que se autoriza el derribo de aeronaves consideradas hostiles o una amenaza para la soberanía y la seguridad nacional. También se encontró que la legislación nacional peruana destaca por lo explícito de las definiciones, principios, lineamientos y procedimientos que se implementan para el proceso de interceptación de una aeronave hostil. Este detalle en la legislación puede ser el resultado de la lamentable situación que se presentó en 2001 cuando, una serie de errores llevaron a que, una aeronave civil que no se encontraba en una actividad ilegal fuera derribada por aviones de la FAP (ver capítulos uno y dos).

En el caso de Colombia y México, estos países no cuentan con una legislación nacional o federal, a diferencia de Perú y Bolivia, sino con una reglamentación que explica bajo qué principios, lineamientos, procedimientos y fases se procederá a la interceptación de una aeronave declarada hostil o ilícita rebelde. Sin embargo, una diferencia sustancial entre el caso colombiano y mexicano consiste en que, en el segundo caso, no se tiene contemplado el uso de la fuerza y abrir fuego para la inutilización o derribo de la aeronave declarada como ilícita rebelde. En contraste, en el caso de Colombia, sí se permite proceder al uso de fuerza letal en aire y/o tierra para aquellas aeronaves hostiles que omitan las indicaciones y/o abran fuego contra la aeronave interceptora de la Fuerza Aérea Colombiana.

Por tanto, un hallazgo de este estudio es que la normatividad aplicable para operaciones de interdicción aérea contra aeronaves ilícitas u hostiles en América Latina presenta variaciones en los alcances jurídicos y en los procedi- 
mientos disponibles. En tres de los casos analizados se autoriza el derribo de la aeronave declarada hostil; sin embargo, en el caso mexicano no se contempla el derribo de la aeronave ilícita rebelde.

\section{Referencias}

ABC News. (3 de febrero de 2010). Mother and Infant Shot Out of the Sky [Archivo de video]. Recuperado de https://www.youtube.com/watch?$\mathrm{v}=\mathrm{XgOU} 6 \mathrm{MtTblA}$

Colprensa. (3 de septiembre de 2002). Comandante de la FAC revela avances del proceso de interdicción "vamos a usar radares propios con radares. $E l$ País. C12, B91.

Gómez, S. (26 de abril de 2001). E.U. suspende interceptación aérea. El Tiempo [en línea]. Recuperado de https://www.eltiempo.com/archivo/ documento/MAM-541122

Guevara, I. (2016). A Bond Worth Strengthening. Understanding the Mexican Military and U.S.-Mexican Military Cooperation. Wilson Center. Mexico Institute. United States of America.

Guevara, I. (2011). Adapting, transforming and modernizing under fire: the mexican military 2006-2011. Strategic Studies Institute. U.S. Army War College, Carlisle, PA. The Lefort Papers. United States of America.

Hernández, C. (24 de mayo de 2018). Bolivia presume de comprar los radares más avanzados de la región. Infodefensa.com [en línea]. Recuperado de https:/www.infodefensa.com/latam/2018/05/24/noticia-bolivia-presume-comprar-radares-avanzados-region.html

Ley 30339, 2015 (29 de agosto) Ley de Control, Vigilancia y Defensa del Espacio Aéreo Nacional. Diario Oficial de la República del Perú No. 13377. Ley 521, 2014 (22 de abril) Ley de Seguridad y Defensa del Espacio Aéreo. Gaceta Oficial del Estado Plurinacional de Bolivia.

Moyano, C. (1993). El protocolo de Montreal de 1984 y la violación del espacio aéreo por aeronaves civiles. Boletin Mexicano de Derecho Comparado, 1 (76).

Organización de Aviación Civil Internacional [OACI]. (2016). Resoluciones vigentes de la Asamblea (al 6 de octubre de 2016). Recuperado de https:// www.icao.int/Meetings/a39/Documents/Resolutions/10075_es.pdf 
Páez, A. (9 de febrero de 2010). Perú: CIA y militares discrepan en caso de avión de misioneros. Inter Press Service [en línea]. Recuperado de http:// www.ipsnoticias.net/2010/02/peru-cia-y-militares-discrepan-en-caso-de-avion-de-misioneros/

Respuesta por parte de la SEDENA a la solicitud de información (folio 0000700063320) realizada a través de la Plataforma Nacional de Transparencia.

Secretaría de Comunicaciones y Transportes (2019). Manual de Publicación de Información Aeronáutica AIP de México (2019). Extracto de la sección 1.12 relativa a "Interceptación de Aeronaves Civiles".

Subsecretaría de Lucha contra el Narcotráfico. (2016). Manual Básico de Precursores Químicos. Recuperado de https://www.mpf.gob.ar/procunar/files/2016/11/PRECURSORES-QUÍMICOS-Manual-básico.pdf

Unidad Administrativa Especial de Aeronáutica Civil [UAEAC]. (s.f.). Rac 5. Reglamento del Aire. Recuperado de http://www.aerocivil.gov.co/normatividad/VERSION\%20OCT\%2015\%202015/RAC\%20\%205\%20 -\%20Reglamento\%20del\%20Aire.pdf 